\title{
Microstructured Reactor as a Pre-Turbo Catalytic Converter
}

\author{
M. Iwaniszyn $\cdot$ J. Ochońska $\cdot$ P. Jodłowski · \\ J. Łojewska $\cdot$ A. Matuszek-Chmurowska $\cdot$ \\ A. Kołodziej
}

Published online: 27 February 2013

(c) The Author(s) 2013. This article is published with open access at Springerlink.com

\begin{abstract}
The idea of a structured catalytic converter placed immediately after engine exhaust valves, thus operating on high gas temperature and velocity, is explored. The assumption is that major part of the reactor operates in the entry region where Nusselt and Sherwood numbers are highly enhanced. In this work, flow resistances as well as heat and mass transfer coefficients were studied for gas velocities exceeding $50 \mathrm{~m} / \mathrm{s}$. Consequently, the transition range (between laminar and turbulent flows) was reached. The comparison with classic monolith has shown significant improvement in heat or mass transfer paid by slight increase in flow resistance.
\end{abstract}

Keywords Heat transfer - Mass transfer - Flow resistance $\cdot$ Catalytic converter $\cdot$ High velocity

\section{List of Symbol}

a Specific surface area, $\mathrm{m}^{-1}$

A, B Constants

$\mathrm{C}_{\mathrm{D}} \quad$ Drag coefficient

M. Iwaniszyn $(\square) \cdot$ A. Kołodziej

Institute of Chemical Engineering, Polish Academy of Sciences,

Bałtycka 5, 44-100 Gliwice, Poland

e-mail: miwaniszyn@iich.gliwice.pl

J. Ochońska $\cdot$ P. Jodłowski $\cdot$ J. Łojewska

Faculty of Chemistry, Jagiellonian University, Ingardena 3,

30-060 Kraków, Poland

A. Matuszek-Chmurowska · A. Kołodziej

Faculty of Civil Engineering, Opole University of Technology,

Katowicka 48, 45-061 Opole, Poland
$\mathrm{D}_{\mathrm{A}} \quad$ Kinematic diffusivity, $\mathrm{m}^{2} \mathrm{~s}^{-1}$

$\mathrm{D}_{\mathrm{h}} \quad 4 \varepsilon / \mathrm{a}$, hydraulic diameter, $\mathrm{m}$

$\mathrm{D}_{\mathrm{p}} \quad$ Grains diameter, $\mathrm{m}$

f Fanning friction factor

$\mathrm{G}_{\mathrm{Z}} \quad$ Graetz number

$\mathrm{k}_{\mathrm{C}} \quad$ Mass transfer coefficient, $\mathrm{m} / \mathrm{s}$

$\mathrm{k}_{\mathrm{r}} \quad$ Kinetic rate constant, $\mathrm{m} / \mathrm{s}$

L Channel length, $m$

$\mathrm{L}_{\mathrm{R}} \quad$ Reactor length, $\mathrm{m}$

$\mathrm{L}^{+} \mathrm{L} /(\mathrm{Dh} \cdot \mathrm{Re})$, hydraulic dimensionless channel length

$\mathrm{L}^{*} \quad \mathrm{~L} /(\mathrm{Dh} \cdot \mathrm{Re} \cdot \mathrm{Pr})$, heat dimensionless channel length

$\mathrm{L}^{* \mathrm{M}} \mathrm{L} /(\mathrm{Dh} \cdot \mathrm{Re} \cdot \mathrm{Sc})$, mass dimensionless channel length

$\mathrm{Nu} \quad \alpha \cdot \mathrm{D}_{\mathrm{h}} / \lambda$, Nusselt number

$\operatorname{Pr} \quad \mathrm{C}_{\mathrm{p}} \cdot \eta / \lambda$, Prandtl number

$\operatorname{Re} \quad \mathrm{w}_{0} \cdot \rho \cdot \mathrm{D}_{\mathrm{h}} /(\varepsilon \cdot \eta)$, Reynolds number

Sc $\quad \eta /\left(\rho \cdot \mathrm{D}_{\mathrm{A}}\right)$, Schmidt number

Sh $\quad \mathrm{k}_{\mathrm{c}} \mathrm{D}_{\mathrm{h}} / \mathrm{D}_{\mathrm{A}}$, Sherwood number

$\mathrm{W}_{0} \quad$ Superficial gas velocity, $\mathrm{m} / \mathrm{s}$

$\alpha \quad$ Heat transfer coefficient, $\mathrm{W} \mathrm{m}^{-2} \mathrm{~K}^{-1}$

$\Delta \mathrm{P} \quad$ Pressure drop (flow resistance), $\mathrm{Pa}$

$\varepsilon \quad$ Void volume

$\eta \quad$ Dynamic viscosity, $\mathrm{Pa} \mathrm{s}$

$\lambda$ Thermal conductivity, $\mathrm{W} \mathrm{m}^{-1} \mathrm{~K}^{-1}$

$\rho \quad$ Density, $\mathrm{kg} \mathrm{m}^{-3}$

$\chi \quad$ Efficiency criterion, eqs. (9) and (10)

\section{List of Subscripts}

fd Fully developed flow

$\mathrm{H}$ Boundary condition of constant heat flux

$\mathrm{T}$ Boundary condition of constant surface temperature

tr Triangular structure

sn Sinusoidal structure 


\section{Introduction}

Effective control of vehicle engine emission, especially that of Diesel engines, constitutes a serious problem because of lean combustion conditions, high amount of nitrogen oxides and production of particulate matter. Therefore, novel methods of controlling $\mathrm{CO} / \mathrm{NO}_{\mathrm{x}}$ emissions are still proposed to enhance the effectiveness of classic monolithic converters. For example, More et al. [1] suggested preliminary pollution reduction in a small converter placed before the turbocharger. Assumed gas velocity may reach $100 \mathrm{~m} / \mathrm{s}$. The authors [1] postulated that up to $70 \%$ of pollution may be neutralized within this small reactor. The above idea is a challenge for all: catalysis, material and chemical engineering. This pre-turbo converter should be designed to operate at high gas temperature and velocity. This may bring about erosion of catalyst and even converter substrate (usually ceramic or metallic monolith).

Few years ago, Kołodziej and Łojewska [2] and Kołodziej et al. [3] designed and modeled metallic shortchannel structures, which base on the assumption of developing laminar flow [4]. The short monolith proposed in [1] follows the idea of the short-channel reactor [2,3] for much higher flow velocities with possibility to reach the transition or even turbulent flow regime. For this reason, heat and mass transfer coefficients should be much higher than in classic monolithic converters.

As excessive heat and mass transfer resistances may significantly reduce the yield of catalytic reactor, particularly monolithic one, the idea of small converter operating in very severe flow regime seems attractive, however, very difficult to achieve. In fact, velocity suggested in [1] exceeds many times that commonly applied in chemical reactors and to our knowledge there is no information on the functioning the structured reactors in the literature.

The purpose of this work was to test the short-channel structures described in [2,3] for very high gas velocities, about $50 \mathrm{~m} / \mathrm{s}$, to meet and experimentally check the demands presented in [1].

\section{Experimental}

Two types of structures were tested: of sinusoidal and triangular channel cross-section. The structures were made of
metal-Kanthal, steel containing $20 \% \mathrm{Cr}$ and 3-5\% Al. Each structure was composed of two type strips stacked alternately and welded: straight strips and wavy (sinusoidal structure) or zigzag (triangular structure) strips. Both strips displayed very close electrical resistance. Table 1 contains the parameters of the tested structures and of the ceramic monolith and packed bed taken for comparison.

Heat transfer and flow resistance experiments were performed using the same methodology as described by Kołodziej and Łojewska [2]. Electric current that heated the structures flowing directly through them reached up to $150 \mathrm{~A}$. Air fed to the reactor was used under ambient temperature and temperatures slightly above the ambient ones (till $50{ }^{\circ} \mathrm{C}$ ). Air velocity reached slightly above $50 \mathrm{~m} / \mathrm{s}$ (limit of the apparatus). Temperatures of the flowing air and of the structure surface were measured using several thermocouples. Special composite glue providing good heat conduction and no electric conduction was used to fix the thermocouples to the channel walls. During the flow resistance experiment, the Recknagel micromanometer was used that ensured resolution of $0.05 \mathrm{~Pa}$ and reproducibility of $0.2 \mathrm{~Pa}$.

The experiments were performed at ambient conditions for a velocity of $50 \mathrm{~m} / \mathrm{s}$. However, usual temperature of the exhaust gases (catalytic combustion or deNOx process) amounts to $400{ }^{\circ} \mathrm{C}$ at least. The Reynolds numbers reached during the experiments (cf. Table 1) correspond, at $400{ }^{\circ} \mathrm{C}$, to a velocity of $\sim 150 \mathrm{~m} / \mathrm{s}$.

\section{Results and Discussion}

The main purpose of this study was to determine the flow resistance, heat and mass transfer in the short-channel triangular and sinusoidal structures under very high gas velocities. The range of Reynolds numbers used (cf. Table 1) proved that not only the laminar, but also the transition flow occurred in the channels.

In short capillary channels the developing laminar flow lead to enhanced transport coefficients, even more within the transient flow range. Unfortunately, in this developing region (or entrance channel section) the flow resistance is also higher comparing with the fully developed flow.

Fanning friction factors, f, defined by Darcy-Weisbach equation:

Table 1 Parameters of the short-channel structures studied

\begin{tabular}{llllll}
\hline Structure & $\begin{array}{l}\text { Channel length } \\
\mathrm{L},(\mathrm{mm})\end{array}$ & $\begin{array}{l}\text { Specific surface } \\
\mathrm{a},\left(\mathrm{m}^{-1}\right)\end{array}$ & $\begin{array}{l}\text { Void } \\
\text { volume }(\varepsilon)\end{array}$ & $\begin{array}{l}\text { Hydraulic diameter } \\
\mathrm{D}_{\mathrm{h}},(\mathrm{mm})\end{array}$ & $\begin{array}{l}\text { Reynolds } \\
\text { range studied }\end{array}$ \\
\hline Triangular (base $5.26 \mathrm{~mm}$; height $4.72 \mathrm{~mm})$ & 5 & 1314.4 & 0.945 & 2.876 & $59.8-6810.6$ \\
Sinusoidal (base $4.06 \mathrm{~mm}$; height $2.19 \mathrm{~mm})$ & 5 & 2382.7 & 0.904 & 1.518 & $38.2-4232.3$ \\
Monolith $100 \mathrm{cpsi}$ & 200 & 1339 & 0.72 & 2.15 & - \\
Packed bed of $2 \mathrm{~mm}$ spheres & - & 1570 & 0.48 & $2.0\left(\mathrm{D}_{\mathrm{P}}\right)$ & - \\
\hline
\end{tabular}


$\frac{\Delta P}{L}=2 f \frac{w_{0}^{2} \rho}{\varepsilon^{2} D_{h}}$

depends on hydraulic dimensionless channel length, $\mathrm{L}^{+}$:

$L^{+}=\frac{L}{D_{h} \operatorname{Re}}$

The correlations for triangular and sinusoidal structures are, respectively:

$$
\begin{aligned}
& (f \cdot \mathrm{Re})_{t r}=2.044 L^{+(-0,631)} \\
& (f \cdot \mathrm{Re})_{s n}=0.774 L^{+(-0,687)}
\end{aligned}
$$

78 experiments were executed for each structure. The average error does not exceed $1 \%$ for both cases. Figure 1 compares both experimental and theoretical results: flow resistance results, correlations derived, theoretical solution of Fleming and Sparow [5] for laminar developing flow in short triangular (equilateral) channel and the dependence proposed by Shah [6] for fully developed laminar flow in triangular and sinusoidal channel.

In the case of triangular structure the experimental points lie close to the theoretical solution of Fleming and Sparow [5] (line 1 and eq. 3 in Fig. 1). However, the results obtained for sinusoidal structure lie below the theoretical solutions of Fleming and Sparow [5] (line 1 and eq. 4 , in fact, for the triangular channel) and even below the solution for fully developed laminar flow (line 3-Shah [6]).

As the independent mass transfer experiments were not performed, the heat and mass transfer analogy was used to derive the mass transfer characteristics. This approach was applied and experimentally proved in [7]; a wide discussion of the problem is presented in [8]. The correlations for

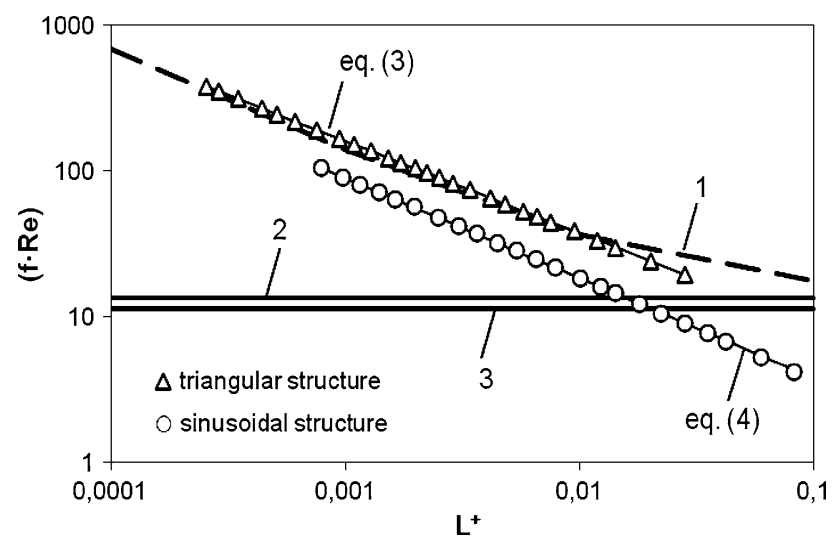

Fig. 1 Flow resistance results in terms of the $(f \bullet R e)$ product vs. dimensionless channel length $\mathrm{L}^{+}$(selected experimental points). 1 theoretical solution of Fleming and Sparow [5] (developing flow); theoretical solutions of Shah [6] for fully developed laminar flow: 2 triangular structure $(\mathrm{f} \bullet \operatorname{Re}=13,333) ; 3$ sinusoidal structure $(\mathrm{f} \bullet \operatorname{Re}=11,256)$ heat (mass) transfer for triangular and sinusoidal structures are:

$$
\begin{aligned}
N u_{t r} & =N u_{H}\left[0,532\left(\operatorname{Pr} \cdot L^{*}\right)^{-0,161}\right] \\
S h_{t r} & =S h_{H}\left[0,532\left(S c \cdot L^{* M}\right)^{-0,161}\right] \\
N u_{s n} & =N u_{T}\left[1,399\left(\operatorname{Pr} \cdot L^{*}\right)^{-0,209}\right] \\
S h_{s n} & =S h_{T}\left[1,399\left(S c \cdot L^{* M}\right)^{-0,209}\right]
\end{aligned}
$$

The number of experimental points was 258 for both, triangular and sinusoidal structures. The average error for triangular structure amounts to $6 \%$ while for sinusoidal structure-7\%. $\mathrm{Nu}_{\mathrm{H}}$ and $\mathrm{Nu}_{\mathrm{T}}$ (analogically $\mathrm{Sh}_{\mathrm{H}}$ and $\mathrm{Sh}_{\mathrm{T}}$ ) are Wibulswas' [9] theoretical solutions for $<\mathrm{H}>$ (constant heat flux) and $<\mathrm{T}>$ (constant wall temperature) boundary conditions:

$$
\begin{aligned}
& N u_{H}=3,111+0,448 \cdot\left(L^{*}\right)^{-0,608} \\
& S h_{H}=3,111+0,448 \cdot\left(L^{* M}\right)^{-0,608} \\
& N u_{T}=2,47+0,299 \cdot\left(L^{*}\right)^{-0,598} \\
& S h_{T}=2,47+0,299 \cdot\left(L^{* M}\right)^{-0,598}
\end{aligned}
$$

The heat transfer results and correlations with theoretical solutions of Wibulswas [9] are presented in Fig. 2. The mass transfer description is analogical.

Figure 2 shows that, for large Reynolds numbers (small $L^{*}$ ), Nusselt numbers are higher than theoretical solution of Wibulswas found for triangular structures [9] (line 2 in Fig. 2). This is because the Wibulswas' [9] solution applies to laminar flow, while the experiments achieved the transition flow regime. The discrepancy between the experiments and the theory is not big in the case of triangular structure. For the sinusoidal structure the differences

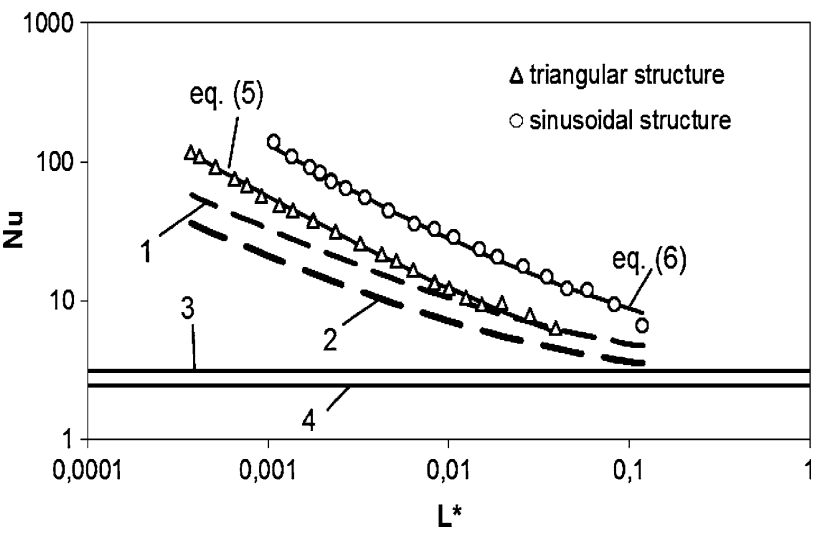

Fig. 2 Heat transfer results in terms of the Nusselt number versus dimensionless channel length $\mathrm{L}^{*}$ (selected experimental points). Theoretical solutions of Wibulswas [9] for developing flow: $1<\mathrm{H}>$ boundary solution; $2<\mathrm{T}>$ boundary solution. Theoretical values for fully developed flow [4]: 3 triangular structure $(\mathrm{Nu}=3,111) ; 4$ sinusoidal structure $(\mathrm{Nu}=2,47)$ 
Table 2 Pressure drop for different types of pre-turbo reactor filling

\begin{tabular}{llll}
\hline Reactor structure & $\mathrm{Re}$ & $\begin{array}{l}\Delta \mathrm{P}[\mathrm{kPa}] \\
\mathrm{L}_{\mathrm{R}}=10 \mathrm{~mm}\end{array}$ & $\begin{array}{l}\Delta \mathrm{P}[\mathrm{kPa}] \\
\mathrm{L}_{\mathrm{R}}=20 \mathrm{~mm}\end{array}$ \\
\hline $\begin{array}{c}\text { Triangular short- } \\
\text { channel structure }\end{array}$ & 2,300 & 0.78 & 1.56 \\
$\begin{array}{c}\text { Sinusoidal short- } \\
\text { channel structure }\end{array}$ & 1,300 & 0.67 & 1.34 \\
$\begin{array}{c}\text { Monolith } 100 \mathrm{cpsi} \\
\begin{array}{c}\text { Packed bed of } 2 \mathrm{~mm} \\
\text { spheres }\end{array}\end{array}$ & 1,630 & 0.81 & 1.17 \\
\hline
\end{tabular}

Temperature $400{ }^{\circ} \mathrm{C}$, atmospheric pressure, superficial gas velocity $\mathrm{w}_{0}=50 \mathrm{~m} / \mathrm{s}$

between the experiments and the Wibulswas' [9] prediction for triangular channel are significant. However, the theoretical solution for laminar flow developing in a sinusoidal channel is not available in the literature. Therefore, Wibulswas' [9] solution is the only possibility to compare the experiments with theoretical prediction. Sinusoidal channel slightly ressemble the triangular one with rounded corners.

The experimentally obtained ranges of Nusselt numbers drop into the range from 5.2 to 122 ( $\mathrm{Sh}=8.4-264)$ for the triangular structure and-from 6.6 to 139.8 ( $\mathrm{Sh}=9.0$ 288) for the sinusoidal structure, which agrees well with the $\mathrm{Nu}$ and $\mathrm{Sh}$ range from 4 to 100 postulated by More et al. [1].

A question arises whether the pressure drop is acceptable for a reactor working with such a large velocity. The reactor (pre-turbo converter) length $\mathrm{L}_{\mathrm{R}}$ assumed was 10 or $20 \mathrm{~mm}$. This is in accordance with the concept of pre-turbo converter presented by More et al. [1] as this reactor type is expected to realise $50-70 \%$ of total conversion at very short distance. Resulting pressure drop for the structures considered are presented in Table 2.

As visible, the pressure drop of structures is almost two orders of magnitude lower than that of packed bed. The pressure drop of short-channel structures is close to the monolith. Such a short monolith $(10-20 \mathrm{~mm})$ may be regarded as a short-channel structure as well. The flow resistance seems acceptable for very short reactors considering high temperature near to the exhaust valve, very intense mass transfer and large available pressure of the exhaust gas in this region of an engine (near to the exhaust valve).

A comparison of the short-channel structures studied with the ceramic monolith $100 \mathrm{cpsi}$ and packed bed, in terms of mass transfer and flow resistance, is presented in Figs. 3 and 4, respectively. Hawthorn [10] correlations were used to calculate Sherwood numbers and Fanning friction factors of the monolith. Sherwood numbers of the packed bed was calculated using Wakao and Kaguei [11] correlation and flow resistance was calculated using Ergun

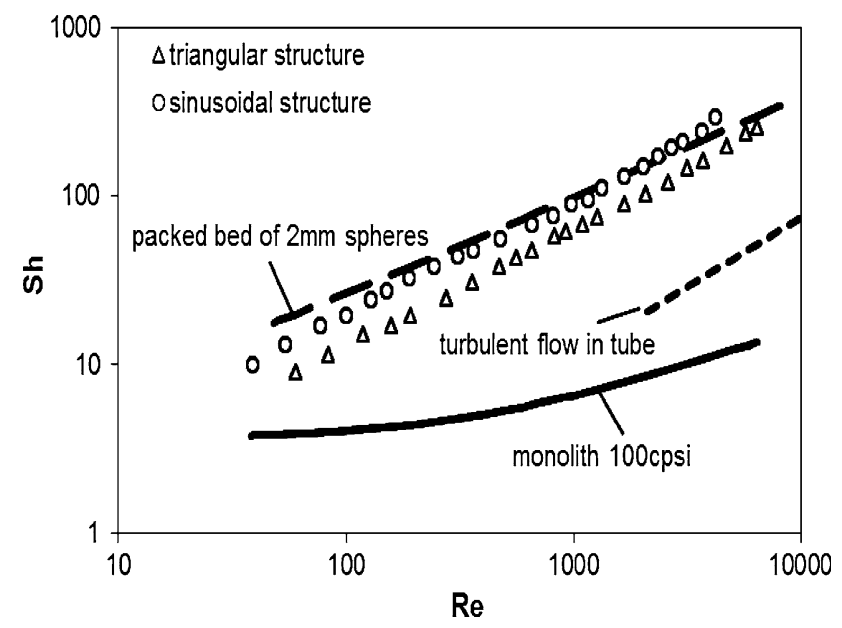

Fig. 3 Mass transfer for short-channel structures (selected experimental points) and monolith $t r$ triangular structure, $s n$ sinusoidal structure, 1 packed bed of $2 \mathrm{~mm}$ spheres, 2 monolith $100 \mathrm{cpsi}, 3$ turbulent flow in tube

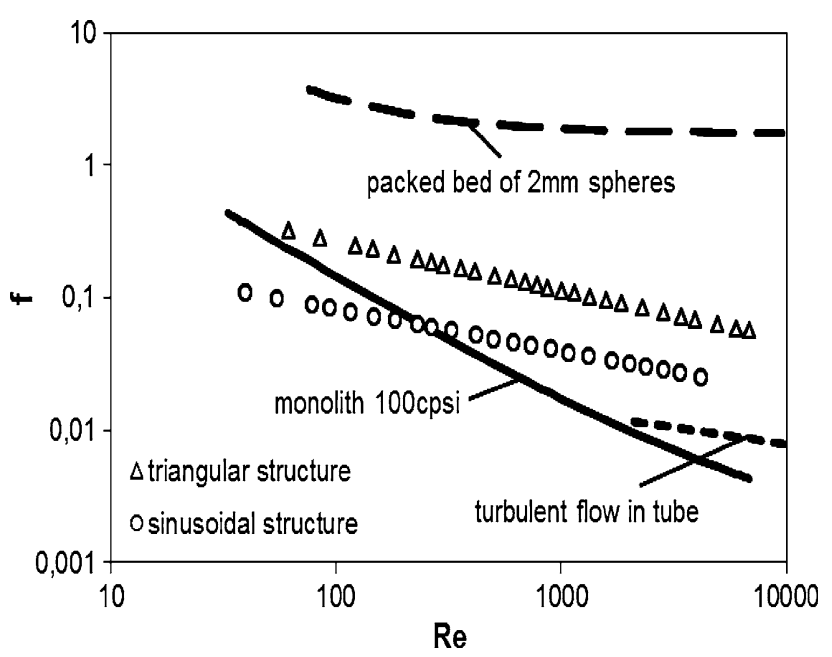

Fig. 4 Flow resistance for short-channel structures (selected experimental points) and monolith (selected experimental points) and monolith. $t r$ triangular structure, $s n$ sinusoidal structure, 1 packed bed of $2 \mathrm{~mm}$ spheres (Ergun model), 2 monolith 100cpsi (Hawthorne model [10]), 3 turbulent flow in tube (Blasius formula)

equation. In the case of the turbulent flow, the flow resistance results were obtained using Blasius equation and the mass transfer results were calculated using the classic equation applied for the turbulent flow in tube: $\mathrm{Sh}=0.023 \mathrm{Re}^{0,83} \mathrm{Sc}^{0,44}$ [12] (similar formula, known as McAdams equation, operated for heat transfer).

As it is shown in Fig. 3 mass transfer for triangular and sinusoidal structures is one order of magnitude higher than those of monolith and comparable with the packed bed. It is noticeable that shortening the channel length (40 times) improved the mass transfer coefficient (Sherwood number) 2 till 30 times. The flow resistance for short-channel structures almost comparable with monolith was rated as a success. 

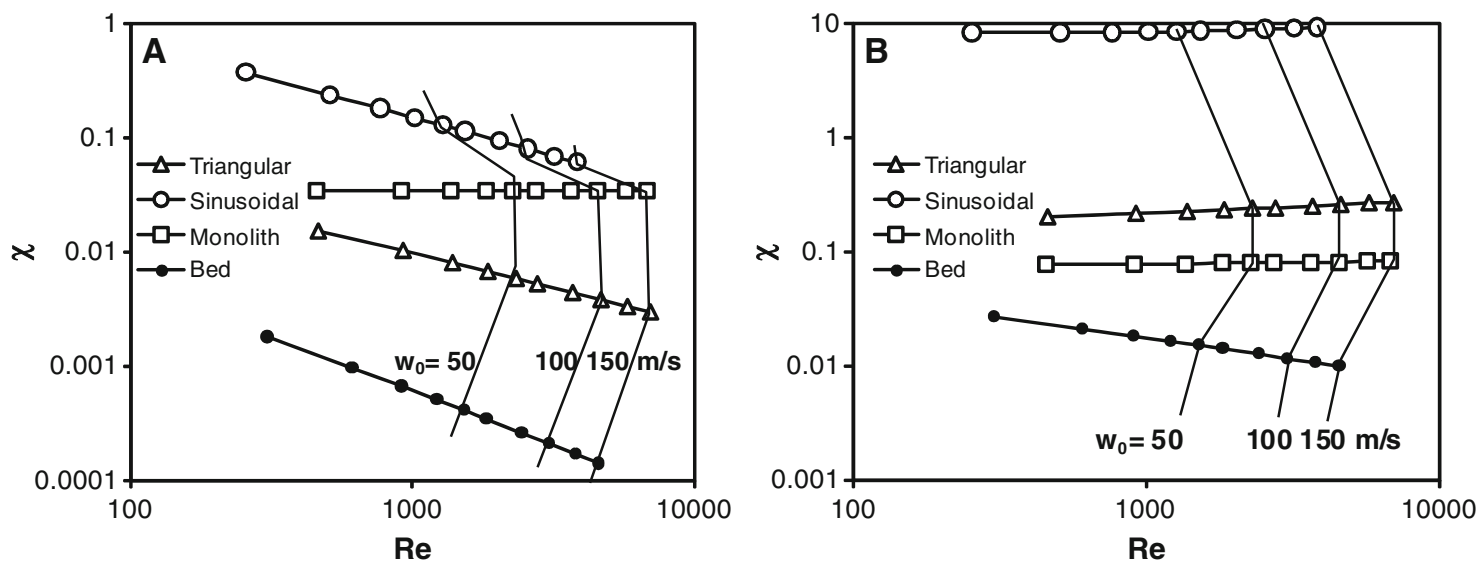

Fig. 5 Efficiency criterion $\chi$ versus Re number: a for the kinetics of Bennet et al. [13], $\chi$ defined by eq. (9), $\mathbf{b}$ for very fast kinetics, $\chi$ defined by eq. (10). Thin solid lines connect points of specified gas velocity $\mathrm{w}_{0}$

It is not easy to compare the particular solutions considering both transfer properties and pressure drop. The efficiency criteria proposed in [2] enable to compare structure taking into account flow resistance, mass transfer and reaction kinetics. For an arbitrary kinetics, the criterion $\chi$ is defined:

$\chi=\frac{k_{C} a}{1+k_{C} / k_{r}} \frac{D_{h}}{4 w_{0} f}$

and for very fast kinetics $\left(\mathrm{k}_{\mathrm{r}} \rightarrow \infty\right)$

$\chi=\frac{k_{C} \varepsilon}{w_{0} f}$

The details are presented in [2]. The comparison of the efficiencies for the both cases presented above is shown in Fig. 5. In the Figure, the corresponding gas velocities are shown in the form of diagram. The experiments were performed at temperature close to the ambient one and with gas velocities up to $50 \mathrm{~m} / \mathrm{s}$. When considering typical engine exhaust conditions $\left(400{ }^{\circ} \mathrm{C}\right)$, the experimentally studied $\mathrm{Re}$ range (Table 1 ) covers linear velocities up to $150 \mathrm{~m} / \mathrm{s}$.

For the kinetics of Bennett et al. [13], sinusoidal shortchannel structure displays the highest efficiency, next classic monolith and triangular structure. However, for very fast kinetics kinetics $\left(\mathrm{k}_{\mathrm{r}} \rightarrow \infty\right)$ the best in again sinusoidal structure, next the triangular one and monolith. Fast reaction kinetics is advantageous to short-channel structures. The packed bed displays the worst efficiency for both cases considered.

\section{Conclusions}

Pioneering transfer and friction experimental study was performed on short-channel structures that operated at very high gas velocities, about $50 \mathrm{~m} / \mathrm{s}$ (laminar and transient flow). Friction factors and Nusselt (Sherwood) numbers were experimentally measured and correlated as functions of dimensionless channel length. The correlations covered both laminar developing flow and transient flow ranges with satisfactory accuracy. The heat (mass) transfer correlations were based on the theoretically derived solutions for developing laminar flow supplemented by experimentally derived correction terms.

Short-channel structures display highly enhanced transfer properties in comparison with classic monoliths under high gas velocities. Nusselt (Sherwood) numbers are over one order of magnitude higher. Particularly, heat (or mass) transfer properties of sinusoidal structure are promising within transient region. The transfer properties enhanced by up to 30 times are paid by only moderate increase in flow resistance.

The efficiencies of the short-channel structures, particularly of the sinusoidal ones, are excellent, especially for very fast kinetics. The short-channel structures seem very efficient solution for the pre-turbo catalytic converter.

Acknowledgments This study was supported by the grants from the Polish National Science Centre (Grants N N523 556638 and N N209 119137) and by the project from Polish Science Foundation financed by EU structural funds (BRIDGE).

Open Access This article is distributed under the terms of the Creative Commons Attribution License which permits any use, distribution, and reproduction in any medium, provided the original author(s) and the source are credited.

\section{References}

1. More H, Mmbaga J, Hayes RE, Votsmeier M, Checkel MD (2007) Top Catal 42-43:429

2. Kołodziej K, Łojewska J (2007) Chem Eng Process 46:637 
3. Kołodziej K, Łojewska J, Ochońska J, Łojewski T (2011) Chem Eng Process 50:869

4. Shah RK, London AL (1978) Laminar flow forced convection in ducts. Academic Press, New York

5. Fleming DP, Sparow EM (1969) J Heat Transf 91:345

6. Shah RK (1975) Int J Heat Mass Transf 18:849

7. Kołodziej A, Łojewska J (2009) Catal Today 147S(suppl):S120

8. Iwaniszyn M, Jaroszyński M, Ochońska J, Łojewska J, Kołodziej A (2011) Scientific Publications of IICh PAN 15:37 (available at: http://www.iich.gliwice.pl/files/303/Zeszyt\%2015\%20(2011).pdf pages 37-46) Accessed 5 Feb 2013

9. Wibulswas P (1966) Laminar-Flow Heat-Transfer in Non-Circular Ducts. Ph.D. Thesis, London University, London, 1966
10. Hawthorn RD (1974) Afterburner catalysis-effects of heat and mass transfer between gas and catalyst surface, AIChE Symp. Ser. 70(137):428

11. Wakao N, Kaguei S (1982) Heat and mass transfer in packed beds. Girdon and Breach Science Publisher, New York

12. Gilliland ER, Sherwood TK (1934) Ind Eng Chem 26:516, 26:1093

13. Bennett CJ, Kolaczkowski AT, Thomas WJ (1991) Trans Inst Chem Eng B 69:209 